\title{
Cost-Effectiveness Analysis of Dimethyl Fumarate in the Treatment of Relapsing Remitting Multiple Sclerosis: An Italian Societal Perspective
}

\author{
Lorenzo Giovanni Mantovani ${ }^{1}$, Gianluca Furneri ${ }^{2}$, Rossella Bitonti ${ }^{2}$, Paolo Cortesi ${ }^{1}$, \\ Elisa Puma ${ }^{3}$, Laura Santoni ${ }^{3}$, Luca Prosperini ${ }^{4}$ \\ Research Centre on Public Health (CESP), University of Milan - Bicocca, Milan, Italy \\ EBMA Consulting, Health Economics, Pricing \& Market Access Department, Melegnano (MI), Italy \\ Biogen Italia, Milan, Italy \\ 4 Dept. of Neurosciences, S. Camillo-Forlanini Hospital, Rome, Italy
}

\section{ABSTRACT}

BACKGROUND: Delayed-release dimethyl fumarate (also known as gastro-resistant dimethyl fumarate, hereafter dimethyl fumarate) is an oral disease-modifying therapy used for the treatment of Relapsing-Remitting Multiple Sclerosis (RRMS), an autoimmune chronic inflammatory condition of the central nervous system.

OBJECTIVE: The objective of this economic analysis was to compare cost-effectiveness of dimethyl fumarate with the alternatives used as first-line treatment of RRMS in Italy.

METHODS: The analysis was conducted from the Italian societal perspective. Health outcomes and costs were evaluated over a 50-year time horizon (equivalent to a lifetime horizon). Both health outcomes and costs were discounted at 3.5\%. The cost-effectiveness analysis was conducted by adapting a Markov model, already used in previous similar economic analyses conducted in RRMS, to the Italian context. The Markov model estimated the clinical and economic consequences of treating RRMS patients with the following therapeutic options: dimethyl fumarate; interferon (IFN) beta-1a subcutaneous (SC) at two different doses, $22 \mathrm{mcg}$ and $44 \mathrm{mcg}$; IFN beta-1b SC; glatiramer acetate (GA) SC $20 \mathrm{mg}$; oral teriflunomide. Clinical efficacy data were retrieved from an elaboration of an already published mixed treatment comparison (MTC). Both direct and indirect costs (disability, treatment acquisition, administration, monitoring, relapses, adverse events) were included in the analysis. One-way and probabilistic sensitivity analyses were carried out and cost-effectiveness acceptability curves generated.

RESULTS: In the base-case analysis, dimethyl fumarate was more efficacious than alternatives, in terms of both survival (19.634 vs. 19.440-19.600 life years for alternatives), and quality-of-life-adjusted survival (6.526 vs. 5.143- 6.189 QALYs for alternatives). The total lifetime cost per patient treated with dimethyl fumarate $(€ 954,286)$ was lower than that of the other DMTs included in the analysis. Therefore, dimethyl fumarate was dominant compared with all analyzed alternatives. Dimethyl fumarate was also the therapeutic option with the highest benefit on disease burden. In fact, costs of disability management were lower than those of all the other first-line drugs included in the analysis. The results of one-way deterministic sensitivity analysis and probabilistic sensitivity analysis confirmed the reliability of base-case results.

CONCLUSIONS: The results of the cost-effectiveness analysis confirm that dimethyl fumarate is an optimal first-line treatment for RRMS in Italy, compared with the other first-line alternatives included in the economic analysis, when evaluated from the societal perspective.
\end{abstract}

\section{Keywords}

Dimethyl Fumarate, Disease-Modifying Therapy, Relapsing-Remitting Multiple Sclerosis, Cost-Effectiveness, Society

\section{INTRODUCTION}

Multiple Sclerosis (MS) is an autoimmune chronic inflammatory condition of the nervous system. MS prevalence is about 2.1 to 2.3 million people all over the world, including around 600,000 in Europe [1] and 118,000 in Italy, where the estimated incidence is about 3,400 cases/year [2]. Onset in full working age, chronicity and typically progressive disability 
heavily affect patients' quality of life, and trigger considerable societal costs [3,4]. The annual cost of MS in Italy is estimated at $€ 5$ billion [2]. The estimated average cost per patient/year from the perspective of the Italian society (i.e., including direct and indirect costs) amounts to $€ 45,000$ [2]. It varies from $€ 22,900$ in patients with mild disability (Expanded Disability Status Scale [5] (EDSS) score: $0-3$ ), to $€ 40,100$ in patients with moderate disability (EDSS: 4-6.5), to $€ 53,300$ in patients with severe disability (EDSS: 7-9) [6]. Relapsing-remitting multiple sclerosis (RRMS) is the most common form of MS, accounting for $65 \%$ of the total number of MS patients worldwide [7]. Prevention of relapses and control of disability progression are by far the most important clinical objectives in RRMS. Over the last decades, the introduction of disease-modifying therapies (DMTs) contributed to change the natural history of RRMS and improve patients' health status. First-line treatments such as interferon (IFN) beta and glatiramer acetate (GA) showed to be effective in limiting the neurological activity of the disease, reducing the risk of relapse, and delaying disability progression [8-11]. Nevertheless, an unmet clinical need in RRMS still remained. A certain proportion of patients do not adequately respond to these first-line DMTs. Furthermore, the use of first-line injectable therapies is associated with tolerability issues, most commonly with flu-like symptoms and injection site reactions, that may negatively impact on the quality of life and adherence [12]. More recently, novel treatments have been approved for the RRMS treatment, thus offering physicians and patients new options to contain the burden of the disease [13-15]. The development of these new oral therapies (delayed-release dimethyl fumarate also known as gastro-resistant dimethyl fumarate $[15,16]$ and teriflunomide $[14,17]$ ) has been carried out to address the above-mentioned unmet needs in RRMS, simplify treatment paradigm, improve quality of life and provide therapeutic options with a different mechanism of action, compared to injectable therapies.

The objective of the analysis was to compare the cost-effectiveness profile of delayedrelease dimethyl fumarate (hereafter defined as "dimethyl fumarate", for simplicity), vs. different alternatives used as first-line treatment of RRMS in Italy from the societal perspective. In this evaluation, the costs were measured in monetary units (euros) and the clinical effects in quality-adjusted life years (QALYs).

\section{MATERIALS AND METHODS}

\section{Study design}

The present cost-effectiveness analysis was conducted by adapting a Markov model (Figure 1), already used in previous, similar economic analyses conducted in RRMS [18-20], to the Italian context. The Markov model simulates the clinical history of the study population and estimates the clinical and economic consequences of treating with different first-line therapeutic options available in Italy. Pharmacological treatments of RRMS slow disability progression, occurrence of relapses, positively affecting quality of life, and favorably impacting life expectancy and costs. At the beginning of the simulation (baseline), patients are affected by RRMS and their disability level (measured through the EDSS [5]) can range from 0 to 6 . Over time, EDSS score of each patient may increase (due to disability progression), decrease (disability remission), or stay unchanged (disability maintenance). Additionally, patients may have a certain risk of progressing to Secondary Progressive Multiple Sclerosis (SPMS). The probability of disability progression depends on MS form (RRMS or SPMS) and on EDSS score. The model consists of 21 health states: 10 states corresponding to the possible 10 disability levels (i.e. EDSS scores) in the RRMS form; 10 states corresponding to the possible 10 EDSS disability levels in the SPMS form; 1 death health state. The Markov model is based on one-year cycles. It was assumed that: i) treatments did not have any effect in preventing transition from RRMS to SPMS and in delaying disability progression in the SPMS form; ii) RRMS patients with EDSS score $\geq 7$, and patients affected by SPMS (any EDSS level) did not receive disease-modifying treatment.

The model captures the most relevant clinical outcomes in RRMS, such as disability progression (through EDSS levels), occurrence of relapses, transition from RRMS to SPMS, and finally mortality of patients. As a result, it is possible to estimate patients' overall survival (measured in life-years: LYs), quality-of-life-adjusted survival (measured in quality-adjusted life-years: QALYs), and overall costs.

In the analysis, dimethyl fumarate (TECFIDERA ${ }^{\circledR}-$ Biogen Netherlands B.V.) was evaluated vs. some of other pharmacological therapies used for the first-line treatment of RRMS in Italy: i) IFN beta-1a, subcutaneous (REBIF ${ }^{\circledR} 22 \mathrm{mcg}$; REBIF ${ }^{\circledR} 44 \mathrm{mcg}$ - Merck Europe B.V.); 
ii) IFN beta-1b, subcutaneous (BETAFER$\mathrm{ON}^{\circledR}$ - Bayer AG, EXTAVIA ${ }^{\circledR}$ - Novartis Europharm Ltd); iii) GA $20 \mathrm{mg}$, subcutaneous $\left(\right.$ COPAXONE $^{\circledR} 20 \mathrm{mg}$ - Teva Pharmaceuticals Ltd), iv) teriflunomide, oral (AUBA$\mathrm{GIO}^{\circledR}$ - Sanofi-Aventis Groupe). A societal perspective (including direct and indirect costs) was adopted to estimate the cost-effectiveness profile of the single alternatives over a 50-year time horizon (lifetime, considering that the analysis applies to a population of subjects in adulthood at the beginning of the simulation). Based on The National Institute for Health and Care Excellence (NICE) recommendations [21], a discount rate of 3.5\% was applied to both the costs and the clinical results of the model after the first year of simulation.

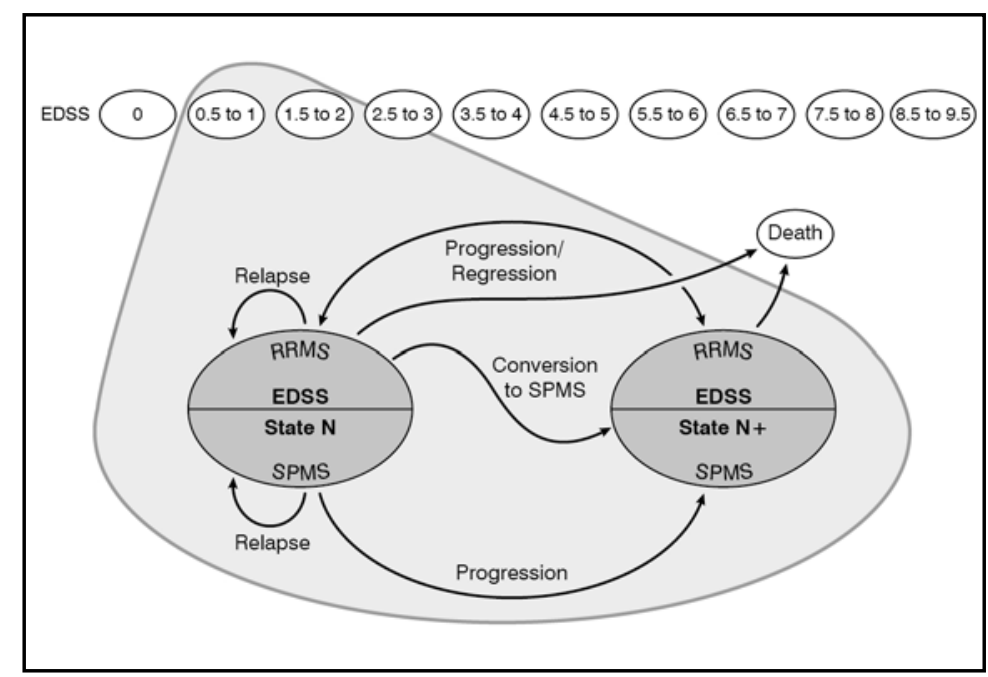

Figure 1. Scheme of the Markov model. Adapted from [20]

EDSS $=$ Expanded Disability Status Scale; RRMS = Relapsing-Remitting Multiple Sclerosis; SPMS $=$ Secondary Progressive Multiple Sclerosis

\section{Data source}

\section{Baseline characteristics}

The study population was a hypothetical cohort of Italian RRMS patients who were eligible to first line DMTs. Patients' clinical characteristics at baseline (age, gender, EDSS score) were derived from dimethyl fumarate clinical trials (CONFIRM [22], DEFINE [23]). The mean age of the cohort at the beginning of the simulation was 37.8 years and the percentage of male patients was $28.6 \%$. The average EDSS score was 2.72 ; the initial distribution of the EDSS score is reported in Table I.

The probabilities used to describe the natural history of the disease were derived from the dimethyl fumarate clinical trials (CONFIRM [22], DEFINE [23]) and from the London Ontario database, one of the most comprehensive and long-lasting observational registries on patients with multiple sclerosis, which collected patient information between 1972 and 2000 [24-26].

The annual relapse rates in absence of treatment were obtained from the dimethyl fumarate clinical trials $[22,23]$, which documented relapse occurrence in the 12 months preceding study entry, for patients with EDSS $<5$. The trend of relapses for EDSS levels $>5$ was obtained from the study conducted by Patzold et al. [27]. Finally, relapse incidence data for patients affected by SPMS were obtained from the elaboration of a survey conducted in the UK [28].

Mortality rates, stratified by age and gender, were extracted from national registries of the Italian Statistics Institute (ISTAT) [29]. Such mortality rates have been adjusted by the additional death risk attributable to MS [30].

Furthermore, the impact of treatment-related adverse events (AEs) was assessed. For all the evaluated drugs, only serious and non-serious AEs occurring in dimethyl fumarate registrative studies were considered. All common AEs of dimethyl fumarate (annual incidence $\geq 5 \%$ ) were included in the analysis. In addition, all AEs occurring with an annual incidence difference $\geq 3 \%$ between dimethyl fumarate and placebo were included in the analysis, regardless of the incidence of the event in the dimethyl fumarate group. The annual incidence of treatment-related AEs was calculated from a systematic review of the literature [31], using a weighted average between the studies.

\begin{tabular}{lccccccccccc}
\hline \multicolumn{1}{c}{ Baseline data } & \multicolumn{10}{c}{ EDSS level } \\
\cline { 2 - 11 } & $\mathbf{0}$ & $\mathbf{1}$ & $\mathbf{2}$ & $\mathbf{3}$ & $\mathbf{4}$ & $\mathbf{5}$ & $\mathbf{6}$ & $\mathbf{7}$ & $\mathbf{8}$ & $\mathbf{9}$ \\
\hline Proportion of patients (\%) & 5.05 & 8.52 & 34.08 & 22.94 & 20.64 & 8.65 & 0.12 & 0.00 & 0.00 & 0.00 \\
$\begin{array}{l}\text { ARR - RRMS form, natural history } \\
\text { (n. of events per year) }\end{array}$ & 1.26 & 1.32 & 1.32 & 1.35 & 1.36 & 1.43 & 1.18 & 1.23 & 1.23 & 1.23 \\
$\begin{array}{l}\text { ARR - SPMS form, natural history } \\
\text { (n. of events per year) }\end{array}$ & 0.00 & 0.00 & 0.91 & 1.64 & 1.05 & 1.27 & 1.10 & 0.82 & 0.82 & 0.82 \\
\hline
\end{tabular}

Table I. Baseline distribution by EDSS and related ARRs, in absence of treatment [22-28]

$\mathrm{ARR}=$ Annualized Relapse Rate; EDSS = Expanded Disability Status Scale; RRMS = Relapsing-Remitting Multiple Sclerosis; SPMS = Secondary Progressive Multiple Sclerosis 


\begin{tabular}{lcc}
\hline \multicolumn{1}{c}{ Treatment } & CDW3M: HR vs. placebo (Cl 95\%) & ARR: RR vs. placebo (Cl 95\%) \\
\hline IFN beta-1a $-22 \mathrm{mcg}$, three times a week & $0.7300(0.6156-0.8657)$ & $0.7165(0.6232-0.8238)$ \\
IFN beta-1a $-44 \mathrm{mcg}$, three times a week & $0.6433(0.5342-0.7747)$ & $0.6648(0.5983-0.7386)$ \\
IFN beta-1 $\mathrm{b}^{1}-250 \mathrm{mcg}$, every other day & $0.8779(0.6198-1.2433)$ & $0.6682(0.5956-0.7497)$ \\
IFN beta-1 $\mathrm{b}^{2}-250 \mathrm{mcg}$, every other day & $0.8779(0.6198-1.2433)$ & $0.6682(0.5956-0.7497)$ \\
Glatiramer acetate $-20 \mathrm{mg}$, daily & $0.8448(0.6887-1.0362)$ & $0.6411(0.5815-0.7068)$ \\
Teriflunomide $-14 \mathrm{mg}$, daily & $0.7106(0.5736-0.8803)$ & $0.7113(0.6224-0.8129)$ \\
Dimethyl fumarate $-240 \mathrm{mg}$, twice daily & $0.6051(0.4713-0.7767)$ & $0.5269(0.4507-0.6159)$ \\
Placebo & Reference & Reference \\
\hline
\end{tabular}

Table II. Treatment efficacy vs. placebo for relapse rate and disability progression [32]

${ }^{1}$ Betaferon $^{\circledR}$

${ }^{2}$ Extavia $^{\circledR}$

$\mathrm{ARR}=$ Annualized Relapse Rate; CDW3M = disability worsening confirmed at 3 months; $\mathrm{Cl}=$ Confidence Interval; IFN = interferon; HR = Hazard Ratio; $\mathrm{RR}=$ Risk Ratio

\section{Clinical data}

Annual disability transition probabilities in the untreated population (measured through EDSS scores) were derived from dimethyl fumarate clinical trials (CONFIRM [22], DEFINE [23]) for RRMS EDSS states up to 7 and from the London Ontario dataset [24] for RRMS EDSS states 7-9 and for the SPMS form (see Appendix, Table IA). Transition probabilities from RRMS to SPMS were derived from the London Ontario dataset [24] (see Appendix, Table IIA). Pharmacological treatment has the effect of modifying the natural evolution of the disease, by: i) limiting or delaying the progression towards higher levels of EDSS in the RRMS form; ii) decreasing the burden of relapses. Both clinical efficacy results were derived from an elaboration of the Mixed Treatment Comparison (MTC) conducted by Hutchinson et al. [32] which allowed to separate the specific values for each single interferon from pooled IFN treatments values. The MTC allows to calculate the hazard ratio values for disability worsening confirmed at 3 months (CDW3M) and risk ratio of incidence of relapses, for all active drugs, compared to a common comparator (placebo). Both efficacy results of the effect of treatments on ARR and CDW3M are summarized in Table II.

\section{Quality of life data}

Utilities of patients affected by RRMS, stratified by EDSS level, were obtained from dimethyl fumarate trial data, organizing the observations for each EDSS state and calculating the average EuroQoL 5 dimensions (EQ-5D-5L) score for each state [22,23]. Data are shown in Table III. Disutilities associated with SPMS disease states, as well as disutilities associated with relapse occurrence, were obtained by correcting RRMS-related utility values collected in dimethyl fumarate trials, for deterioration factors (i.e., disutilities), obtained from the survey conducted in the UK [28]. The disutility factors associated with SPMS and relapse occurrence

\begin{tabular}{ccccc}
\hline \multirow{2}{*}{ EDSS level } & \multicolumn{2}{c}{ With relapses } & \multicolumn{2}{c}{ Without relapses } \\
\cline { 2 - 5 } & RRMS & SPMS & RRMS & SPMS \\
\hline 0 & 0.8660 & 0.8223 & 0.8752 & 0.8315 \\
1 & 0.8250 & 0.7814 & 0.8342 & 0.7905 \\
2 & 0.7710 & 0.7274 & 0.7802 & 0.7365 \\
3 & 0.6855 & 0.6418 & 0.6946 & 0.6509 \\
4 & 0.6161 & 0.5725 & 0.6253 & 0.5816 \\
5 & 0.5350 & 0.4913 & 0.5442 & 0.5005 \\
6 & 0.4463 & 0.4027 & 0.4555 & 0.4118 \\
7 & 0.3346 & 0.2909 & 0.3437 & 0.3000 \\
8 & -0.0068 & -0.0505 & 0.0023 & -0.0413 \\
9 & -0.1793 & -0.2229 & -0.1701 & -0.2138 \\
\hline
\end{tabular}

Table III. Utilities by EDSS level, MS form and presence/absence of relapse $[22,23,28]$

EDSS $=$ Expanded Disability Status Scale; RRMS = Relapsing-Remitting Multiple Sclerosis; SPMS $=$ Secondary Progressive Multiple Sclerosis (applied on an annual basis in both cases) amounted to -0.0437 and -0.0092 , respectively.

The model incorporated disutilities for AEs; such disutilities depend on the type of AE and the degree of severity (serious/ non-serious) and have a temporary effect on patients' quality of life (from a minimum of one day per year up to a maximum of six months per year, for some events such as fatigue and flu-like symptoms). Since all data were not available in literature, these values have been estimated and validated by clinical experts.

\section{Economic data}

According to the societal perspective, this economic analysis considered the following costs: disability, treatment acquisition, administration, monitoring, relapses, AEs. 


\begin{tabular}{ccccccccccc}
\hline \multirow{2}{*}{ MS form } & \multicolumn{10}{c}{ EDSS level } \\
\cline { 2 - 12 } & $\mathbf{0}$ & $\mathbf{1}$ & $\mathbf{2}$ & $\mathbf{3}$ & $\mathbf{4}$ & $\mathbf{5}$ & $\mathbf{6}$ & $\mathbf{7}$ & $\mathbf{8}$ & $\mathbf{9}$ \\
\hline RRMS costs $(€)$ & 1,375 & 1,375 & 1,375 & 12,770 & 12,770 & 12,770 & 12,770 & 34,904 & 34,904 & 34,904 \\
SPMS costs $(€)$ & 9,644 & 9,644 & 9,644 & 51,613 & 51,613 & 51,613 & 51,613 & 76,251 & 76,251 & 76,251 \\
\hline
\end{tabular}

Table IV. Disability-related costs for RRMS and SPMS forms [33,34]

RRMS and SPMS: disability costs included direct medical costs (DMTs, co-medications, OTC drugs, visits, monitoring, etc.), direct non-medical costs (informal care, investments/modifications), indirect costs (sick leave, retirement due to MS).

RRMS 0-6: the value on table 4 regarding direct medical costs includes only the costs for co-medications and OTC drugs. Not included the costs for DMTs and other disease management costs (e.g., monitoring, etc.) considered in other calculation sections of the model

EDSS = Expanded Disability Status Scale; RRMS = Relapsing Remitting Multiple Sclerosis; SPMS = Secondary Progressive Multiple Sclerosis

\begin{tabular}{|c|c|c|}
\hline Treatment & Ex-factory price ${ }^{1}$ ( $€ / 1$ pack) & Source \\
\hline IFN beta-1a - 22 mcg, three times a week & 764.36 (12 vials, 6 MIU) & Official Journal 145, 2018 [35] \\
\hline IFN beta- $1 \mathrm{a}-44$ mcg, three times a week & $1,027.75$ (12 vials, $12 \mathrm{MIU})$ & Official Journal 145, 2018 [35] \\
\hline IFN beta- $1 b^{2}-250$ mcg, every other day & 856.01 (15 vials, $250 \mathrm{mcg}$ ) & $\begin{array}{l}\text { Official Journal 127, } 2000 \text { [36] } \\
\text { Supplement } 250 \text { Official Journal 279, } 2007 \text { [37] }\end{array}$ \\
\hline IFN beta- $1 b^{3}-250 \mathrm{mcg}$, every other day & 856.02 (15 vials, $250 \mathrm{mcg})$ & Official Journal 66, 2009 [38] \\
\hline Glatiramer acetate - 20 mg, daily & 769.30 (28 vials, 20 mg) & Official Journal 106, 2005 [39] \\
\hline Teriflunomide - 14 mg, daily & 1,027.75 (28 tablets, $14 \mathrm{mg})$ & Official Journal 187, 2014 [17] \\
\hline Dimethyl fumarate - $240 \mathrm{mg}$, twice daily & 1,153.00 (56 capsules, 240 mg) & Official Journal 19, 2015 [16] \\
\hline
\end{tabular}

Table V. Acquisition costs of the drugs included in the analysis

${ }^{1}$ It does not include temporary law reductions and discounts applied to public structures of Italian NHS

2 Betaferon ${ }^{\circledR}$

${ }^{3}$ Extavia $^{\circledR}$

IFN = interferon; MIU = Million International Units

Disability-related costs, including indirect costs, were obtained from the study conducted by Karampampa et al. [33]. To date, this is the only Italian study that evaluated costs by MS form. Table IV reports disability-related costs included in the model, expressed in euros inflated to June 2018 [34]. For EDSS levels 0-6 in RRMS form only costs for co-medications are included. The costs for DMTs and other disease management costs (e.g., monitoring) are considered in other calculation sections of the model and described below.

The economic impact of pharmacological treatment was expressed as annual cost per patient calculated on the ex-factory price per pack (Table V), net of temporary law reductions and discounts applied to public structures of Italian National Healthcare Service (NHS), multiplied by the number of units needed to cover 1 year of treatment.

Administration costs were assumed equal to $€ 0$ as all treatments included in the analysis can be self-administered. Annual monitoring costs were calculated assuming that the patients would be compliant with main monitoring recommendations for RRMS [40] (Table VI).

The social cost of relapse management costs was derived from Battaglia et al. [6] and then inflated from $€ 2,600$ in December 2015 to $€ 2,660$ in June 2018 [34].

The economic impact of AEs was calculated by multiplying the annual incidence of treatment-related AEs by the corresponding unit costs, weighted by the frequency of grade III/IV cases. It was assumed that mild-tomoderate events were managed either by the general practitioner (GP) [41] or, in majority of cases, by the specialist [42], while severe events were managed in day-hospital or through standard hospitalization [43,44], depending on the event.

\section{Sensitivity analyses}

Both univariate deterministic and multivariate probabilistic sensitivity analyses were conducted to identify model parameters with the largest effect on incremental

\begin{tabular}{|c|c|c|}
\hline Treatment & $\begin{array}{c}\text { Average cost, } \\
\text { Year } 1(€)\end{array}$ & $\begin{array}{c}\text { Average cost, Year } 2 \\
\text { and subsequent ( }())\end{array}$ \\
\hline IFN beta-1a -22 mcg & 1,137 & 412 \\
\hline IFN beta- $1 \mathrm{a}-44 \mathrm{mcg}$ & 1,137 & 412 \\
\hline IFN beta-1 $1 b^{1}-250$ mcg & 1,137 & 412 \\
\hline IFN beta- $1 b^{2}-250$ mcg & 1,137 & 412 \\
\hline Glatiramer acetate - 20 mg & 921 & 328 \\
\hline Teriflunomide - 14 mg & 988 & 350 \\
\hline Dimethyl fumarate - $240 \mathrm{mg}$ & 930 & 334 \\
\hline
\end{tabular}

Table VI. Treatment monitoring costs [40]

${ }^{1}$ Betaferon $^{\circledR}$

${ }^{2}$ Extavia $^{\circledR}$

IFN = interferon 
cost-effectiveness ratio (ICER), and to evaluate the overall robustness of the base-case analysis. In the deterministic sensitivity analysis, the value of each parameter was separately varied to assess the impact on the results. For the deterministic analysis, parameter variation of \pm $10 \%$ around the base-case values were used (analyzed inputs: EDSS state costs, relapse costs, patient utilities, natural history relapse rates, dimethyl fumarate relapse rate, dimethyl fumarate disability progression rate and dimethyl fumarate drop-out rate).

Two additional deterministic sensitivity analyses were conducted as described below.

In the first analysis, disability costs by EDSS (extracted from Karampampa et al. and Iannazzo et al. studies [33,45]) were replaced with costs from Battaglia et al. 2017 study [6]. This study was published more recently, but it did not report stratification of costs by MS form (i.e. RRMS vs. SPMS form). To fill this data gap, a RRMS vs. SPMS cost-ratio was calculated from Karampampa et al. study, and then applied to Battaglia's cost estimates to determine the costs of the two forms of MS considered in the model.

In the second analysis, a comparison between dimethyl fumarate and generic GA $20 \mathrm{mg}$ (COPEMYL ${ }^{\circledR}$ - Mylan S.p.A.) recently placed on the market in Italy [46] was conducted to measure the ICER difference vs. base-case.

The probabilistic sensitivity analysis was performed by simultaneously and randomly varying (through 1,000 replications) the values of all parameters. For the probabilistic analysis, the following probability distributions were used: lognormal for clinical variables (relapse risk reduction, disability progression hazard ratio, AEs incidence, etc.); beta for probabilities and utilities; gamma for costs.

\section{RESULTS}

\section{Base-case}

In the base-case analysis, dimethyl fumarate was more effective than comparators, both in terms of survival (19.634 LYs, compared with 19.440-19.600 LYs for alternatives), and quality-of-life-adjusted survival (6.526 QALYs, compared with 5.143-6.189 QALYs discounted for alternatives) (Table VII). The total lifetime cost per patient treated with dimethyl fumarate $(€ 954,286)$ was lower than for the other alternatives included in the analysis $(€ 962,893$ $1,007,743$ ) (Table VII).

Therefore dimethyl fumarate was dominant (i.e., more effective and less costly) compared with IFNs, GA and teriflunomide, with an ICER ranging between $€-20,627$ and $€-38,639$, significantly below the willingness-to-pay (WTP) threshold of $€ 50,000$ per QALY gained $[47,48]$ (Table VII illustrates the results of the cost-effectiveness analysis).

Dimethyl fumarate was the therapeutic option with the highest benefit on disease burden. In fact, costs of disability management were lower than those of all the other first-line drugs included in the analysis.

\begin{tabular}{|c|c|c|c|c|c|c|c|}
\hline Treatment & $\begin{array}{l}\text { Pharmacological } \\
\text { therapy costs } \\
+ \text { monitoring } \\
\text { costs }(€)\end{array}$ & $\begin{array}{l}\text { Disability } \\
\text { costs } \\
\text { related to } \\
\text { EDSS (€) }\end{array}$ & $\begin{array}{c}\text { Total } \\
\text { costs }(€)\end{array}$ & $\begin{array}{c}\text { Survival } \\
\text { (LYs) }\end{array}$ & $\begin{array}{l}\text { Quality of } \\
\text { life adjusted } \\
\text { survival } \\
\text { (QALY) }\end{array}$ & $\begin{array}{c}\text { ICER } \\
\text { per LY } \\
\text { (DMF vs. } \\
\text { alternative) }\end{array}$ & $\begin{array}{c}\text { ICER } \\
\text { per QALY } \\
\text { (DMF vs. } \\
\text { alternative) }\end{array}$ \\
\hline Dimethyl fumarate - $240 \mathrm{mg}$ & 94,915 & 859,370 & 954,286 & 19.634 & 6.526 & Reference & Reference \\
\hline IFN beta-1a -22 mcg & 64,986 & 904,570 & 969,556 & 19.533 & 5.786 & $\begin{array}{c}\text { DMF } \\
\text { dominates }\end{array}$ & $\begin{array}{c}\text { DMF } \\
\text { dominates }\end{array}$ \\
\hline IFN beta-1a -44 mcg & 86,436 & 876,457 & 962,893 & 19.600 & 6.189 & $\begin{array}{c}\text { DMF } \\
\text { dominates }\end{array}$ & $\begin{array}{c}\text { DMF } \\
\text { dominates }\end{array}$ \\
\hline IFN beta- $1 b^{1}-250 \mathrm{mcg}$ & 66,556 & 941,187 & $1,007,743$ & 19.440 & 5.143 & $\begin{array}{c}\text { DMF } \\
\text { dominates }\end{array}$ & $\begin{array}{c}\text { DMF } \\
\text { dominates }\end{array}$ \\
\hline IFN beta- $1 b^{2}-250 \mathrm{mcg}$ & 62,121 & 941,187 & $1,003,308$ & 19.440 & 5.143 & $\begin{array}{c}\text { DMF } \\
\text { dominates }\end{array}$ & $\begin{array}{c}\text { DMF } \\
\text { dominates }\end{array}$ \\
\hline Glatiramer acetate $-20 \mathrm{mg}$ & 61,029 & 932,747 & 993,776 & 19.459 & 5.341 & $\begin{array}{c}\text { DMF } \\
\text { dominates }\end{array}$ & $\begin{array}{c}\text { DMF } \\
\text { dominates }\end{array}$ \\
\hline Teriflunomide - $14 \mathrm{mg}$ & 72,705 & 898,792 & 971,497 & 19.547 & 5.953 & $\begin{array}{c}\text { DMF } \\
\text { dominates }\end{array}$ & $\begin{array}{c}\text { DMF } \\
\text { dominates }\end{array}$ \\
\hline
\end{tabular}

Table VII. Results of cost-effectiveness analysis (base-case)

${ }^{1}$ Betaferon $^{\circledR}$

${ }^{2}$ Extavia $^{\circledR}$

DMF = Dimethyl Fumarate; EDSS = Expanded Disability Status Scale; ICER = Incremental Cost-Effectiveness Ratio; IFN = interferon; LY = Life-Year 


\section{Sensitivity analysis}

One-way deterministic sensitivity analysis showed that in almost all tested alternative scenarios dimethyl fumarate remained dominant. Only in two cases dimethyl fumarate was not dominant: i) $+10 \%$ dimethyl fumarate disability progression rate, vs. IFN beta-1a $-22 \mathrm{mcg}$ (ICER $=€ 3,161$ per QALY gained); ii) $+10 \%$ dimethyl fumarate disability progression rate, vs. IFN beta-1a $-44 \mathrm{mcg}$ (dimethyl fumarate and IFN beta- $1 \mathrm{a}-44 \mathrm{mcg}$ had similar costs and similar efficacy).

In the two additional deterministic scenarios tested (disability costs from Battaglia et al. [6] and comparison between dimethyl fumarate and generic GA $20 \mathrm{mg}$ ) dimethyl fumarate remained dominant.

Figure 2 shows the results of probabilistic sensitivity analyses, expressed in terms of probability for dimethyl fumarate to be cost-effective or dominant (lower cost and higher health outcomes) with respect to the therapeutic alternatives included in the analysis. Overall, the cost-effectiveness profile of dimethyl fumarate was favorable, since the probability of being dominant compared to the alternatives included in the model was between around $61 \%$ and $92 \%$ and the probability of being cost-effective was between approximately $67 \%$ and $96 \%$ with a WTP threshold of $€ 50,000$ per QALY gained $[47,48]$.

\section{DISCUSSION}

The objective of this economic analysis was to compare cost-effectiveness of first-line alternatives used for the treatment of RRMS, from the Italian societal perspective. To our knowledge, this is one of the first Italian economic analyses adopting a societal perspective as primary analysis. Most economic analyses in Italy are designed to inform budget holders and reimbursement decision makers regarding direct costs supported by the Italian National Healthcare Service (NHS). Although this approach is reasonable and is usually recommended, we believe that any comprehensive health economic analysis should present results under a societal perspective as well, at least in the context of a sensitivity analysis, especially for those conditions, such as multiple sclerosis, where the societal component is extremely relevant. As shown in several economic reports [3,6,33], costs for reduced/lost productivity, out-of-pocket expenses, formal and informal caregiving, home adaptations, etc. have a significant economic impact on patients, families and, more broadly, on the entire social system.

The results of these one-to-one comparisons between dimethyl fumarate and some of the other available options in first-line RRMS show that dimethyl fumarate is a cost-effective option in the treatment of RRMS. In all comparisons dimethyl fumarate resulted dominant (lower costs and better health outcomes) vs. all the alternatives included in the analysis.

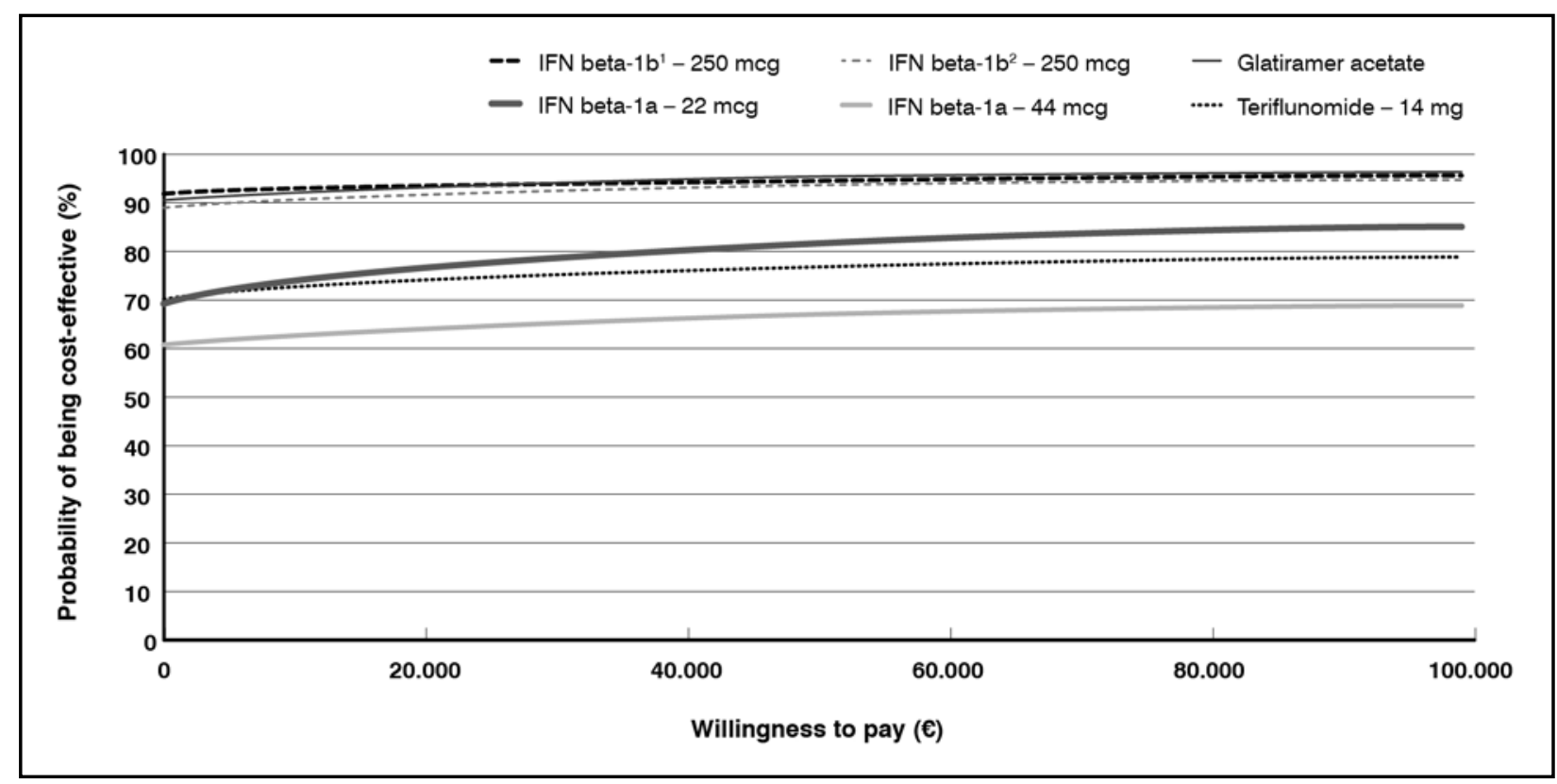

Figure 2. Probabilistic sensitivity analysis: acceptability curves of dimethyl fumarate vs. therapeutic alternatives included in the analysis. ${ }^{1}$ Betaferon ${ }^{\circledR}$

${ }^{2}$ Extavia $^{\circledR}$

IFN = interferon 
Furthermore, the results of one-way deterministic and probabilistic sensitivity analyses confirm the reliability and robustness of base-case results quite convincingly. Two additional scenarios were evaluated. In the first scenario, disability costs by EDSS used in the base-case were replaced with costs reported by Battaglia et al. [6]. This study was published more recently but did not report stratification of costs by MS form (i.e. RRMS vs. SPMS form). To fill this data gap, a RRMS vs. SPMS cost-ratio was calculated from Karampampa et al. study [33] used in the base-case, and then applied to Battaglia's cost estimates to determine the costs of the two forms of MS. Dimethyl fumarate remained dominant in this additional scenario. In the second scenario, a comparison between dimethyl fumarate and generic GA $20 \mathrm{mg}$ recently placed on the market in Italy [46] was conducted to measure the ICER difference vs. basecase. Dimethyl fumarate remained dominant also in this scenario.

This analysis, adopting the Italian societal perspective, reinforces the findings of a previous analysis conducted on dimethyl fumarate and adopting the Italian NHS perspective [49]. Furthermore, the results from the Italian analysis are in line with those reported for USA [50] and other countries of Europe [51-55].

In the context of any economic assessment, it is worth critically appraising the methodology of the analysis, and the main limitations. In our view, the most relevant issue of this economic assessment is the absence of head-to-head studies evaluating dimethyl fumarate vs. other active drugs, designed to test superiority of most important endpoints (relapse occurrence, disability progression). The evidence used to conduct the analysis was derived from a MTC published by Hutchinson et al. [32]. Although the precision of the estimates might be lower than a randomized clinical trial as it combines different sources, the MTC is a common and acceptable approach to assess the relative treatment effects of multiple treatments when these data are not available from head-to-head clinical trials. In addition, the number of MTCs published in recent years has increased exponentially [56] and the use of the MTC tool for conducting drug-economic assessments is well established [57]. Moreover, the assessments conducted by NICE and Scottish Medicine Consortium (SMC) on this MTC have not revealed significant methodological weaknesses as well as the review conducted by the authors of the present economic analysis.

A further limitation of the study was that we could not conduct a cost-effectiveness comparison of dimethyl fumarate vs. two alternatives used in first line treatment of RRMS: IFN beta-1a $30 \mathrm{mcg}$, once a week, intramuscular and GA $40 \mathrm{mg}$, three times a week, subcutaneous. The primary source used to retrieve clinical efficacy data, the MTC conducted by Hutchison et al. [32], did not report results of such comparators.

Another limitation of this analysis is that we were not able to calculate adjusted, countryspecific (i.e. Italian) utility data, as we did not have access to the primary data source (patient level data from registration studies).

Other considerations concern model setting. As shown in the literature, most of the healtheconomic models in multiple sclerosis are based on the principle that pharmacological treatment reduces both disability progression and relapse burden [20,58-60]. The final consequence of this effect is the delay of EDSS progression and of disease transformation from RRMS to SPMS.

With regards to the optimal outcome choice for modelling, there is an interesting debate about the use of new "holistic" parameters, such as the so called "No Evidence of Disease Activity" (NEDA) [61]. NEDA is a composite parameter that includes the following factors: absence of measurable clinical activity (defined as absence of relapse and absence of progression) and absence of activity measured on magnetic resonance. This parameter could be added to the other two outcomes (relapse, progression of disability) to estimate more accurately the clinical benefits of pharmacological treatment.

These considerations appear important for future assessment, when data on composite outcomes of disease activity will be certainly collected more systematically and will induce health economists to modify the clinical framework of economic models. For the time being, we can only assume that, if there is a correlation among reduction of relapse burden, delayed disability progression, and prolongation of active-disease free survival, then a new healtheconomic approach based on NEDA should even favor the most effective therapies, thus confirming dimethyl fumarate dominance, in our specific case.

Furthermore, the model configuration is limited to the first line of treatment and cannot simulate the successive sequences of treatment. Although including this feature would better reflect clinical practice in real world, it could however mask the true value of a specific DMT, as any benefits may result from other subsequent treatments and the benefits/costs of subsequent treatments would also be "diluted" from discounting, placing more weight on sooner 
outcomes. Moreover, none therapeutic algorithm is reported in the Italian guidelines for the MS treatment.

Another consideration could be done. The probabilities used to describe the natural history of the disease were derived in part from the London Ontario database, which collected patient information some decades ago between 1972 and 2000. Despite this, even today The London Ontario study is one of the most comprehensive and long-lasting observational registries on patients with multiple sclerosis.

Furthermore, the AEs included in the model are only those of dimethyl fumarate. This is a conservative assumption and likely can impact the results of the analysis against dimethyl fumarate.

Finally, the analysis does not capture the quality-of-life benefits and any intangible costs associated with a potential switch from injectable therapies (such as IFN and GA) and oral therapies, such as dimethyl fumarate (and teriflunomide). Again, a thorough assessment of such benefits is hard to make because of the lack of ad-hoc data, but it is plausible to assume that the quantification of these factors in the analyses could be favorable to oral therapies vs. injectable therapies.

In conclusion, all the limitations acknowledged in this analysis have been managed with the aim of adopting a conservative approach, thus not favoring dimethyl fumarate.

\section{CONCLUSIONS}

The results of this cost-effectiveness analysis confirm that dimethyl fumarate is an optimal first-line treatment for RRMS in Italy, compared with the other first-line alternatives included in the economic evaluation, when evaluated from the societal perspective.

\section{Acknowledgments}

The authors worked on the development of the manuscript, had full editorial control of the paper and provided their final approval of all content.

\section{Funding}

Biogen Italia (Milan, Italy) provided funding for pharmacoeconomic support on the development of the analysis.

\section{Conflicts of interest}

LGM: research grant from Biogen, Almirall, Roche, Bayer. Speaker's fee from Almirall, Roche, Biogen, Bayer.

GF and RB: EBMA Consulting employees. EBMA Consulting received consulting fees from Biogen Italy for analysis conduction.

PC: research grant from Angelini. Speaker's fee from Pfizer, Roche.

EP and LS: employees of Biogen Italia

LP: has received consulting fees from Biogen, Merck, Novartis and Roche; speaker honoraria from Biogen, Genzyme, Merck Serono, Novartis, Roche and Teva; travel grants from Biogen, Genzyme, Novartis, Roche and Teva; research grants from the Italian MS Society (Associazione Italiana Sclerosi Multipla) and Genzyme. 


\section{APPENDIX}

\begin{tabular}{|c|c|c|c|c|c|c|c|c|c|c|}
\hline \multirow{2}{*}{$\begin{array}{c}\text { From EDSS } \\
\text { level }\end{array}$} & \multicolumn{10}{|c|}{ To EDSS level } \\
\hline & 0 & 1 & 2 & 3 & 4 & 5 & 6 & 7 & 8 & 9 \\
\hline \multicolumn{11}{|c|}{ Transition probabilities for RRMS form } \\
\hline 0 & 0.311 & 0.289 & 0.312 & 0.070 & 0.016 & 0.001 & 0.000 & 0.000 & 0.000 & 0.000 \\
\hline 1 & 0.178 & 0.231 & 0.419 & 0.127 & 0.039 & 0.004 & 0.001 & 0.000 & 0.000 & 0.000 \\
\hline 2 & 0.060 & 0.130 & 0.493 & 0.215 & 0.088 & 0.011 & 0.002 & 0.000 & 0.000 & 0.000 \\
\hline 3 & 0.019 & 0.055 & 0.299 & 0.322 & 0.241 & 0.044 & 0.013 & 0.003 & 0.004 & 0.000 \\
\hline 4 & 0.005 & 0.017 & 0.127 & 0.251 & 0.411 & 0.121 & 0.048 & 0.014 & 0.007 & 0.000 \\
\hline 5 & 0.001 & 0.004 & 0.033 & 0.096 & 0.252 & 0.295 & 0.211 & 0.085 & 0.023 & 0.000 \\
\hline 6 & 0.000 & 0.001 & 0.009 & 0.034 & 0.123 & 0.257 & 0.329 & 0.190 & 0.056 & 0.001 \\
\hline 7 & 0.000 & 0.000 & 0.003 & 0.013 & 0.057 & 0.169 & 0.309 & 0.257 & 0.189 & 0.004 \\
\hline 8 & 0.000 & 0.000 & 0.000 & 0.000 & 0.000 & 0.000 & 0.000 & 0.000 & 0.995 & 0.005 \\
\hline 9 & 0.000 & 0.000 & 0.000 & 0.000 & 0.000 & 0.000 & 0.000 & 0.000 & 0.000 & 1.000 \\
\hline \multicolumn{11}{|c|}{ Transition probabilities for SPMS form } \\
\hline 1 & - & 0.769 & 0.154 & 0.077 & 0.000 & 0.000 & 0.000 & 0.000 & 0.000 & 0.000 \\
\hline 2 & - & 0.000 & 0.636 & 0.271 & 0.062 & 0.023 & 0.008 & 0.000 & 0.000 & 0.000 \\
\hline 3 & - & 0.000 & 0.000 & 0.629 & 0.253 & 0.077 & 0.033 & 0.003 & 0.005 & 0.000 \\
\hline 4 & - & 0.000 & 0.000 & 0.000 & 0.485 & 0.350 & 0.139 & 0.007 & 0.018 & 0.000 \\
\hline 5 & - & 0.000 & 0.000 & 0.000 & 0.000 & 0.633 & 0.317 & 0.022 & 0.026 & 0.002 \\
\hline 6 & - & 0.000 & 0.000 & 0.000 & 0.000 & 0.000 & 0.763 & 0.190 & 0.045 & 0.002 \\
\hline 7 & - & 0.000 & 0.000 & 0.000 & 0.000 & 0.000 & 0.000 & 0.805 & 0.189 & 0.006 \\
\hline 8 & - & 0.000 & 0.000 & 0.000 & 0.000 & 0.000 & 0.000 & 0.000 & 0.926 & 0.074 \\
\hline 9 & - & 0.000 & 0.000 & 0.000 & 0.000 & 0.000 & 0.000 & 0.000 & 0.000 & 1.000 \\
\hline
\end{tabular}

Table IA. Transition probabilities among disability progression levels, by multiple sclerosis form [22-24]

EDSS = Expanded Disability Status Scale; RRMS = Relapsing Remitting Multiple Sclerosis; SPMS = Secondary Progressive Multiple Sclerosis

\begin{tabular}{cc}
\hline EDSS level & Probability \\
\hline 1 & 0.003 \\
2 & 0.032 \\
3 & 0.117 \\
4 & 0.210 \\
5 & 0.299 \\
6 & 0.237 \\
7 & 0.254 \\
8 & 0.153 \\
9 & 1.000 \\
\hline
\end{tabular}

Table IIA. Transition probabilities from RRMS to SPMS form [24]

EDSS = Expanded Disability Status Scale; RRMS = Relapsing Remitting Multiple Sclerosis; SPMS = Secondary Progressive Multiple Sclerosis 


\section{BIBLIOGRAPHY}

1. Canal N, Ghezzi A, Zaffaroni M. Sclerosi multipla. Attualità e prospettive. Milano: Elsevier Health Sciences, 2011

2. Associazione Italiana Sclerosi Multipla (AISM). Barometro Sclerosi Multipla, 2018

3. Kobelt G, Berg J, Lindgren P, et al. Costs and quality of life of patients with multiple sclerosis in Europe. J Neurol Neurosurg Psychiatry 2006; 77: 918-26; https://doi.org/10.1136/ jnnp.2006.090365

4. Phillips CJ, Humphreys I. Assessing cost-effectiveness in the management of multiple sclerosis. Clinicoecon Outcomes Res 2009; 1: 61-78; https://doi.org/10.2147/CEOR.S4225

5. Kurtzke JF. A new scale for evaluating disability in multiple sclerosis. Neurology 1955; 5 : 580-3; https://doi.org/10.1212/WNL.5.8.580

6. Battaglia M, Kobelt G, Ponzio M, et al. New insights into the burden and costs of multiple sclerosis in Europe: Results for Italy. Mult Scler 2017; 23 2: 104-16; https://doi. org/10.1177/1352458517708176

7. Thompson AJ, Baranzini SE, Geurts J, et al. Multiple sclerosis. Lancet 2018; 391: 1622-36; https://doi.org/10.1016/S0140-6736(18)30481-1

8. Johnson KP, Brooks BR, Cohen J a, et al. Copolymer 1 reduces relapse rate and improves disability in relapsing-remitting multiple sclerosis: results of a phase III multicenter, double-blind placebo-controlled trial. The Copolymer 1 Multiple Sclerosis Study Group. Neurology 1995; 45: 1268-76; https://doi.org/10.1212/WNL.45.7.1268

9. Sibley WA. Interferon beta-1b in the treatment of multiple sclerosis: Final outcome of the randomized controlled trial. Neurology 1995; 45: 1277-85; https://doi.org/10.1212/ WNL.45.7.1277

10. Ebers GC. Randomised double-blind placebo-controlled study of interferon beta-1a in relapsing/remitting multiple sclerosis. PRISMS (Prevention of Relapses and Disability by Interferon beta-1a Subcutaneously in Multiple Sclerosis) Study Group. Lancet 1998; 352: 1498-504; https://doi.org/10.1016/S0140-6736(98)03334-0

11. Jacobs LD, Cookfair DL, Rudick RA, et al. Intramuscular interferon beta-1a for disease progression in relapsing multiple sclerosis. The Multiple Sclerosis Collaborative Research Group (MSCRG). Ann Neurol 1996; 39: 285-94; https://doi.org/10.1002/ana.410390304

12. Tremlett HL, Oger J. Interrupted therapy: Stopping and switching of the $\beta$-interferons prescribed for MS. Neurology 2003; 61: 551-4; https://doi.org/10.1212/01.WNL.0000078885.05053.7D

13. European Medicines Agency - EMA. Peginterferon beta-1a (Plegridy). Summary of Product Characteristics. Available at http://www.ema.europa.eu/docs/en_GB/document_library/ EPAR__Product_Information/human/002827/WC500170302.pdf(last accessed September 2018)

14. European Medicines Agency - EMA. Teriflunomide (Aubagio). Summary of Product Characteristics. Available at http://www.ema.europa.eu/docs/en_GB/document_library/ EPAR_-_Product_Information/human/002514/WC500148682.pdf(last accessed September 2018)

15. European Medicines Agency - EMA. Dimethyl-fumarate (Tecfidera). Summary of Product Characteristics. Available at http://www.ema.europa.eu/docs/en_GB/document_library/ EPAR_-_Product_Information/human/002601/WC500162069.pdf (last accessed September 2018)

16. Italian Medicines Agency - AIFA. Reimbursement and selling price of new packages of Tecfidera. Official Journal n. 19 of the Italian Republic of January 12, 2015

17. Italian Medicines Agency - AIFA. Reimbursement and selling price of new packages of Aubagio. Official Journal n. 187of the Italian Republic of August 13, 2014.

18. National Institute for Health and Care Excellence - NICE. Beta interferon and glatiramer acetate for the treatment of multiple sclerosis. Available at https://www.nice.org.uk/guidance/ ta32 (last accessed September 2018) 
19. National Institute for Health and Care Excellence - NICE. Fingolimod for the treatment of highly active relapsing-remitting multiple sclerosis. Available at https://www.nice.org. uk/guidance/ta254 (last accessed September 2018)

20. Gani R, Giovannoni G, Bates D, et al. Cost-effectiveness analyses of natalizumab (Tysabri ${ }^{\circledR}$ ) compared with other disease-modifying therapies for people with highly active relapsingremitting multiple sclerosis in the UK. Pharmacoeconomics 2008; 26: 617-27; https://doi. org/10.2165/00019053-200826070-00008

21. National Institute for Health and Care Excellence - NICE. Guide to the methods of technology appraisal 2013. Available at http://www.nice.org.uk/article/pmg9/chapter/foreword (last accessed September 2018)

22. Gold R, Kappos L, Arnold DL, et al. Placebo-Controlled Phase 3 Study of Oral BG-12 for Relapsing Multiple Sclerosis. N Engl J Med 2012; 367: 1098-107; https://doi.org/10.1056/ NEJMoa1114287

23. Fox RJ, Miller DH, Phillips JT, et al. Placebo-controlled phase 3 study of oral BG-12 or glatiramer in multiple sclerosis. N Engl J Med 2012; 367: 1087-97; https://doi.org/10.1056/ NEJMoa1206328

24. Weinshenker BG, Bass B, Rice GPA, et al. The Natural History Of Multiple Sclerosis: A Geographically Based Study. Brain 1989; 112: 1419-28; https://doi.org/10.1093/ brain/112.6.1419

25. Kremenchutzky M, Rice GPA, Baskerville J, et al. The natural history of multiple sclerosis: A geographically based study 9: Observations on the progressive phase of the disease. Brain 2006; 129: 584-94; https://doi.org/10.1093/brain/awh721

26. Cottrell DA, Kremenchutzky M, Rice GP, et al. The natural history of multiple sclerosis: a geographically based study. 5 . The clinical features and natural history of primary progressive multiple sclerosis. Brain 1999; 122: 641-7; https://doi.org/10.1093/brain/122.4.641

27. Patzold U, Pocklington PR. Course of multiple sclerosis. First results of a prospective study carried out of 102 MS patients from 1976-1980. Acta Neurol Scand 1982; 65: 248-66; https://doi.org/10.1111/j.1600-0404.1982.tb03084.x

28. UK Multiple Sclerosis Survey. Patient demographics, regression model on EDSS, relapse, type of MS and other variables on utility derived from EQ-5D. 2007

29. National Institute of Statistics of Italy (ISTAT). Mortality rates, 2016

30. Pokorski RJ. Long-term survival experience of patients with multiple sclerosis. J Insur Med 1997; 29: 101-6

31. Systematic review and mixed treatment comparison of MS therapies. Report (Data on file). December 2014

32. Hutchinson M, Fox RJ, Havrdova E, et al. Efficacy and safety of BG-12 (dimethyl fumarate) and other disease-modifying therapies for the treatment of relapsing-remitting multiple sclerosis: a systematic review and mixed treatment comparison. Curr Med Res Opin 2014; 30: 613-27; https://doi.org/10.1185/03007995.2013.863755

33. Karampampa K, Gustavsson A, Miltenburger C, et al. Treatment experience, burden and unmet needs (TRIBUNE) in MS study: results from five European countries. Mult Scler 2012; 18: 7-15; https://doi.org/10.1177/1352458512441566

34. National Institute of Statistics of Italy (ISTAT). Inflation rates. Available at http://rivaluta. istat.it/Rivaluta (last accessed September 2018)

35. Italian Medicines Agency - AIFA. Renegotiation of the medicinal product for human use «Rebif». Determina n. 866/2018. Italian Official Journal n. 145, June 25th, 2018

36. Italian Medicines Agency - AIFA. Reimbursement and selling price of Betaferon. Official Journal n. 127 of the Italian Republic of June 02, 2000

37. Italian Medicines Agency - AIFA. Reimbursement and selling price of new packages of Betaferon. Official Journal n.279 of the Italian Republic Supplement n.250 of November 30,2007 
38. Italian Medicines Agency - AIFA. Reimbursement and selling price of new packages of Extavia. Official Journal n. 66 of the Italian Republic of March 20, 2009

39. Italian Medicines Agency - AIFA. Marketing authorization for the medicinal product "Copaxone”. Official Journal n. 106 of the Italian Republic of May 9, 2005

40. Clinical expert opinion to determine monitoring costs associated to multiple sclerosis disease modifying therapies. Data on file. June 2018

41. Garattini L, Castelnuovo E, Lanzeni D, et al. Duration and cost of general practitioner visits. The DYSCO project. Farmeconomia Health Economics and Therapeutic Pathways 2003; 4: 109-14; https://doi.org/10.7175/fe.v4i2.773

42. Italian Ministry of Health. Outpatient intervention tariffs. Italian Republic Official Gazette. Chapter n. 23; Supplement n. 8; 28 January 2013

43. Italian Ministry of Health, Department of Planning of the National Healthcare Service. Hospital activity and analysis of hospital discharge forms in 2014.

44. Italian Ministry of Health. Inpatient intervention tariffs. Italian Republic Official Gazette. Chapter n. 23; Supplement n. 8; 28 January 2013

45. Iannazzo S, Santoni L, Saleri C, et al. Cost-effectiveness analysis of peginterferon beta-1a in Italian relapsing remitting multiple sclerosis management. Farmeconomia Health Economics and Therapeutic Pathways 2016; 17: 13-36; https://doi.org/10.7175/fe.v17i2S.1230

46. Italian Medicines Agency - AIFA. Marketing authorization for the human medicinal product «Copemyl». Official Journal n. 6 of the Italian Republic of January 09, 2017

47. Messori A, Santarlasci B, Trippoli S, et al. Economic value of the drug and clinical benefit: state of the art of the methodology and application of a pharmacoeconomic algorithm. PharmacoEconomics Italian Research Articles 2003; 5: 53-67; https://doi.org/10.1007/ BF03320605

48. Neumann PJ, Cohen JT, Weinstein MC. Updating Cost-Effectiveness - The Curious Resilience of the \$50,000-per-QALY Threshold. N Engl J Med 2014; 371: 796-7; https:// doi.org/10.1056/NEJMp1405158

49. Furneri G, Santoni L, Marchesi G, et al. Cost-Effectiveness Analysis of Delayed-Release Dimethyl-Fumarate In The Treatment of Relapsing-Remitting Multiple Sclerosis In Italy. Value Heal 2015; 18: A697; https://doi.org/10.1016/j.jval.2015.09.2598

50. Zhang X, Hay JW, Niu X. Cost Effectiveness of Fingolimod, Teriflunomide, Dimethyl Fumarate and Intramuscular Interferon- $\beta 1 \mathrm{a}$ in Relapsing-Remitting Multiple Sclerosis. CNS Drugs 2015; 29: 71-81; https://doi.org/10.1007/s40263-014-0207-x

51. Gasche D, Restovic G, Casado V, et al. Cost-Effectiveness Analysis of Delayed-Release Dimethyl Fumarate for The Treatment of Relapsing Remitting Multiple Sclerosis In Spain. Value Heal 2015; 18: A755; https://doi.org/10.1016/j.jval.2015.09.2931

52. Granfeldt D, Björstad A, Öhrman S, et al. The cost effectiveness of delayed-release dimethyl fumarate versus interferon beta-1b in a Swedish setting. Value Heal 2015; 18: A757; https:// doi.org/10.1016/j.jval.2015.09.2467

53. Silva Miguel L, de Sá J, Pinheiro B, et al. Cost-Utility Analysis of Delayed-Release Dimethyl Fumerate For The Treatment of Relapsing-Remitting Multiple Sclerosis In Portugal. Value Heal 2015; 18: A758; https://doi.org/10.1016/j.jval.2015.09.2471

54. Olsen J, Wiren A. Cost-Effectiveness of Dimethyl Fumarate Treatment for RelapsingRemitting Multiple Sclerosis From A Danish Perspective. Value Heal 2015; 18: A758; https://doi.org/10.1016/j.jval.2015.09.2469

55. Chevalier J, Chamoux C, Hammès F, et al. Cost-Effectiveness of Treatments for Relapsing Remitting Multiple Sclerosis: A French Societal Perspective. PLoS One 2016; 11: e0150703; https://doi.org/10.1371/journal.pone.0150703

56. Lee AW. Review of mixed treatment comparisons in published systematic reviews shows marked increase since 2009. J Clin Epidemiol 2014; 67: 138-43; https://doi.org/10.1016/j. jclinepi.2013.07.014 
57. Jansen JP, Fleurence R, Devine B, et al. Interpreting indirect treatment comparisons and network meta-analysis for health-care decision making: Report of the ISPOR task force on indirect treatment comparisons good research practices: Part 1. Value Heal 2011; 14: 417-28; https://doi.org/10.1016/j.jval.2011.04.002

58. Kobelt G, Berg J, Lindgren P, et al. Modeling the cost-effectiveness of a new treatment for MS (natalizumab) compared with current standard practice in Sweden. Mult Scler 2008; 14: 679-80; https://doi.org/10.1177/1352458507086667

59. Lee S, Baxter DC, Limone B, et al. Cost-effectiveness of fingolimod versus interferon beta-1a for relapsing remitting multiple sclerosis in the United States. J Med Econ 2012; 15: 1088-96; https://doi.org/10.3111/13696998.2012.693553

60. Chiao E, Meyer K. Cost effectiveness and budget impact of natalizumab in patients with relapsing multiple sclerosis. Curr Med Res Opin 2009; 25: 1445-54; https://doi. org/10.1185/03007990902876040

61. Giovannoni G, Tomic D, Bright JR, et al. "No evident disease activity": The use of combined assessments in the management of patients with multiple sclerosis. Mult Scler J 2017; 23: 1179-87; https://doi.org/10.1177/1352458517703193 